\title{
Türkiye’de Geleneksel Yöntemlerle Üretilen Peynirlerin Küf Florası
}

\author{
Musa Yalman ${ }^{1}$, Seda Özdikmenli Tepeli ${ }^{1}$, Nükhet Nilüfer Demirel Zorba ${ }^{2 *}$ \\ ${ }^{l}$ Çanakkale Onsekiz Mart Üniversitesi, Yenice Meslek Yüksekokulu, Glda İsleme Bölümü, 17550 Yenice/Çanakkale, Türkiye \\ ${ }^{2}$ Çanakkale Onsekiz Mart Üniversitesi, Mühendislik Fakültesi, Gıda Mühendisliği Bölümü, 17020 Merkez/Çanakkale, Türkiye
}

\section{A K A L E B İ L G İ S İ}

Geliş 11 Nisan 2016

Kabul 16 Ekim 2016

Çevrimiçi bask1, ISSN: 2148-127X

Anahtar Kelimeler:

Peynir

Küf

Geleneksel

Penicillium spp.

Mikotoksin

*Sorumlu Yazar:

E-mail: dnukhet@comu.edu.tr

\section{Ö Z E T}

Ülkemizde geleneksel yöntemler ile üretilen birçok peynir çeşidi vardır. İnek, koyun ve keçi sütlerinden hayvan derisi, çömlek ve benzeri ortamlarda doğal olarak bulunan küfler ile olgunlaştırılan peynirlerde bunlar arasında yer almaktadır. İç Anadolu, Akdeniz ve Doğu Anadolu bölgelerinde üretilen bu peynirlerde kontrolsüz olarak gelişen küfler, ürettikleri sekonder metabolitler nedeni ile halk sağlığı açısından risk oluşturabilir. Küfle olgunlaştırılan peynirlerimizde en çok Penicillium spp. saptandığı, baskın türün spp Penicillium roqueforti olduğu belirlenmiştir. Ayrıca peynirlerde Aspergillus, Alternaria, Mucor, Geotrichum, Cladosporium cinslerine ait türlerinde izole edildiği bildirilmiştir. $\mathrm{Bu}$ küfler arasında mikotoksin oluşturan suşların da olduğu belirlenmiştir. Bu nedenle peynirlerin olgunlaştırılmasının kontrollü olarak yapılması ve kullanılacak starter küf suşlarının seçimi önem taşımaktadır. Çalışmamızda ülkemizde geleneksel yöntemler ile üretilen küflü peynirlerin üretimi hakkında bilgi verilmiş, bu peynirlerin küf florasında hangi küflerin olduğu ve halk sağlığı açısından olabilecek riskler üzerinde durulmuş, ayrıca küfle olgunlaştırılmayan diğer peynirlerdeki küf florasından bahsedilmiş̧ir.

Turkish Journal Of Agriculture - Food Science And Technology, 4(11): 926-933, 2016

\section{Mold Flora of Traditional Cheeses Produced in Turkey}

\section{A R T I C LE IN F O}

Article history:

Received 11 April 2016

Accepted 16 October 2016

Available online, ISSN: 2148-127X

Keywords:

Mold

Cheeses

Traditional

Penicillium spp.

Mycotoxin

*Corresponding Author:

E-mail: dnukhet@ comu.edu.tr

\section{A B S T R A C T}

In our country, there are many cheese types that are produced traditionally. Cheeses which produced from cows, sheep and goat milk that matured with spontaneous growth of molds present in livestock skins, pots and similar environments are among them. They are produced traditionally in Mediterrian, Central and Eastern Anatolia regions. Molds that grow spontaneously in cheeses could create public health risk because of their secondary metabolites. Penicillium spp. are the most isolated mold from these cheeses and Penicillium roqueforti is determined as the dominant species. Furthermore, Aspergillus, Alternaria, Mucor, Geotrichum, Cladosporium species have been isolated. It is very important to control the ripening conditions and starter strain selection since some strains were reported as mycotoxin producers. In this review, it has been tried to give general information about traditional production of mold-ripened cheese in Turkey and the mold flora found in traditional cheeses. In addition, public health risk of these cheeses is reported.

\section{Giriş}

Peynir, yüksek miktarda ve kalitede protein içermesi, yağ, kalsiyum, vitamin A ve vitamin B2 bakımından zengin olmas1 ve kolay sindirilebilir olması nedeniyle günlük beslenmemizde önemli bir yere sahiptir (Özkalp ve Durak, 1998; Akalın, 2011; Kaynar, 2011).

Türk Gida Kodeksi Peynir Tebliğine göre peynir; "Hammaddenin uygun bir pihtılaştırıcı kullanılarak pihtılaştırılması ve pihtıdan peyniraltı suyunun ayrılmasıyla ya da sütün permeatının ayrılmasından sonra pıhtılaştırılmasıyla elde edilen, farklı sertliklerde ve yağ içeriklerinde, salamura ile ya da kuru tuzlama ile tuzlanarak ya da tuzlanmadan, starter kültür kullanarak ya da kullanmadan, telemesi haşlanarak ya da haşlanmadan, çeşnili ya da çeşnisiz olarak, tekniğine uygun olarak üretilen, olgunlaştırılmadan ya da olgunlaştırıldıktan sonra tüketilen, çeşidine özgü karakteristik özellikleri gösteren süt ürünleri” olarak tanımlanmaktadır (Anonim, 2015).

Peynir yapımında kullanılan süt, hayvansal, bitkisel veya mikrobiyel kaynaklardan elde edilen ve yasalarca kullanılmasına izin verilen proteolitik enzimler ve peynir mayası ile pıhtılaştırılır. Bunun yanı sıra, Türk Gıda 
Kodeksi Gıda Katkı Maddeleri Yönetmeliğinde kullanımına izin verilen laktik asit, asetik asit gibi organik asitler veya laktik asit bakterileri, mayalar ve izin verilen küf mikroorganizmalarını bulunduran kültürlerde bu amaçla kullanılabilir (Anonim, 2013). Peynir mayası ile pıhtılaştırılan sütlerin işlenmesi, tuzlanması, yöreye göre ot, baharat ve benzer tat ve koku verici maddeler katıldıktan sonra, mağara, çömlek, bidon, tulum gibi farklı ortamlarda yine peynir çeşidine göre değişen farklı sıcaklık ve sürelerde olgunlaştırılması ile geleneksel peynirler elde edilmektedir (Özkalp ve Durak, 1998).

Türkiye, peynir çeşitleri bakımından zengin bir ülkedir. Ancak tüketimin büyük miktarının yöresel olarak üretilen peynirlerden karşılandığı, bu yöresel peynirlerin ise diğer bölgeler tarafından çok iyi bilinmediği bildirilmektedir (Tarakçı ve Temiz, 2009). Türkiye'de üretilen en önemli peynir çeşitleri, Beyaz, Kaşar ve Tulum peynirleri başta olmak üzere Mihaliç, Dil, Otlu, Çerkez, Hellim, Çayır, Lor ve Civil peynirleridir (Çelik ve Uysal, 2009; Tarakçı ve Temiz, 2009). Dünyada yaklaşık olarak 4000 peynir çeşidi olduğu, Türkiye'de ise Kamber ve Terzi (2008)'ye göre 110'dan fazla, diğer araştırmacılara göre ise 50 den fazla peynir çeşidi olduğu belirtilmektedir (Elmalı ve Uylaşer, 2012). Türkiye İstatistik Kurumu'nun 2015 yılı verilerine göre; Türkiye'de 17.709.101 ton/yıl süt üretilmiş olup, bu sütün 15.987.939 ton/y1l'ını inek sütü, 1.177.227 ton/y1l'ını koyun sütü, 481.174 ton/yıl'ını keçi sütü ve 62.761 ton/yıl'ını ise manda sütü oluşturmaktadır. $\mathrm{Bu}$ sütten 637.284 ton/y1l inek peyniri üretilmiştir. Ayrıca 1.917 ton/y1l koyun peyniri, 337 ton/y1l keçi peyniri, 34 ton/y1l manda peyniri ve karışık sütlerden de 26.008 ton/yıl peynir üretilmiştir (TUİK, 2016).

\section{Küfler İle Olgunlaştırılan Peynirler}

Dünyada küfle olgunlaştırılan peynirler genel olarak Penicillium roqueforti ve Penicillium camembertii türü küfler ile üretilmekte olup ülkelerde ve bölgelerde üretim yöntemleri farklılık göstermektedir (Yetim ve Çakmakçı, 1997). Roquefort, Camembert, Brie, Blue Cheese, Danablu, Mycella, Bayrish-blue, Gorgonzola, Stilton, Danish-blue, Gammelost, Blauschimmelkase küflü peynirleri dünyada en çok bilinenlerdir (Yetim ve Çakmakçı, 1997; Özkalp ve Durak, 1998; Şengün ve ark., 2006).

Ülkemizde beğenilerek tüketilen peynir çeşitlerinden biri de küflü peynirlerdir. Türk Gıda Kodeksi Peynir Tebliği'nde küf kültürleri ile olgunlaştırılan peynir: "kullanımına izin verilen küf kültürleri ile olgunlaştırılan, çeşidine özgü karakteristik özellikler gösteren peynir" olarak tanımlanmış ve küflendirme işlemlerinin kontrollü iklimlendirme sağlanabilen ve hijyen koşulları uygun yerlerde yapılması gerektiğine yer verilmiştir (Anonim, 2015). Ayrıca küf kültürleri ile olgunlaştırılarak üretilen peynirlerin etiketinde kullanılan küf kültürünün yazılması gerektiği de belirtilmiştir.

Türkiye de geleneksel olarak üretilen başlıca küflü peynirler; Divle tulum peyniri, Konya küflü peyniri, küflü tulum peyniri, Göğermiş peyniri, Isparta küflü çömlek (Küp) peyniri, Tomas peyniri, Kayseri çömlek peyniridir (Kamber ve Terzi, 2008; Özgören ve Seçkin, 2012). Evlerde veya küçük işletmelerde üretilen küflü peynirler, geleneksel yöntemler ile starter kültür kullanmadan olgunlaştırma ortamındaki veya ürünün doğal yapısında bulunan küfler ile olgunlaştırılarak üretilmektedir (Özkalp ve Durak, 1998; Şengün ve ark., 2006; Hayaoglu ve Kirbag, 2007; Kamber ve Terzi; 2008; Çakmakçı, 2011; Özgören ve Seçkin, 2012).

Starter kültür ile üretilen peynirlerde, starter olarak kullanılan küf türlerinden yüzeyde gelişmesi istenilen küfler, peynir üretiminde peynir yüzeylerine püskürtülerek, peynir iç kısmında çoğalması istenilen küfler ise süte pıhtı oluşmadan önce ilave edilmektedir. Ambalajlanarak olgunlaştırılan peynirlerde ise starter küfler dolum esnasında ara ara serpilerek inoküle edilmektedir (Yetim ve Çakmakçı, 1997).

Starter olarak seçilecek küflerin, toksijenik ve patojenik özellikte olmaması ve antibiyotik benzeri metabolitler üretmemesi gerekmektedir. $\mathrm{Bu}$ küfler amilolitik, proteolitik ve lipolitik aktiviteye sahip olmalı ve üründe arzu edilen tat, koku ve görünüşü sağlamalıdır. Ayrıca karakteristik küf aromasını ürüne yansıtmalıdır. $\mathrm{Bu}$ kültürler yüzeyde veya gıda içerisinde rahatça gelişebilmeli ve diğer mikroorganizmaların aktivitelerinden etkilenmemelidir. Üründe arzu edilen renk ve miktarda miseller oluşturmalıdır (Yetim ve Çakmakçı, 1997).

\section{Küflü Peynir Üretim Yöntemleri}

Küflü peynirler, genel olarak pastörize edilmemiş yağsız veya kısmen yağı alınmış inek, koyun veya keçi sütünden ya da bunların karışımından oluşan sütler kullanılarak veya yağsız tulum peyniri ya da diğer peynir çeşitlerinin ufalanıp kullanılması ile üretilmektedir. Her iki üretimde de peyniraltı suyunun süzdürülmesi sonrasında çömlek, bidon veya tulumlara hava almayacak şekilde dolum yapılmakta, daha sonra bodrum, mahzen, mağara veya toprak altına gömülerek olgunlaştırılmaktadır. Evlerdeki üretimde süt, ev ortamında başlangiçta herhangi bir kültür veya küf sporları ilave edilmeden $30-32^{\circ} \mathrm{C}$ de dana şirdeni ile pıhtılaştırılır. Peyniraltı suyunun süzülmesi için ve pıhtının bir yapı kazanması için pamuk torbalarda 24 saat bekletilir. Daha sonra pıhtı elle bezelye büyüklüğünde parçalanır ve kuru tuzlama yapılarak tekrar torbaya aktarılır. İlk on gün boyunca torbada ön olgunlaştırmaya bırakılır. Daha sonra çömlek, bidon veya tulumlara sıkıca doldurulur. Sonrasında olgunlaşması için \%80-90 nisbi nemde ve $6-12^{\circ} \mathrm{C}$ 'deki mağaralara, mahzenlere veya toprak altına yerleştirilir (Özkalp ve Durak, 1998; Şengün ve ark., 2006; Kamber ve Terzi, 2008; Özgören ve Seçkin, 2012). Olgunlaşma sonrasında bıçakla bloklar halinde kesilerek peynir yüzeyleri kendiliğinden maviyeşil oluncaya kadar odalarda veya mağaralarda olgunlaştırılır. Küflü peynirlerin olgunlaşması süresince peynir yüzeylerinde, beyaz ile mavi yeşil damarlı küfler oluşmaktadır. Küflü peynirde lezzet ve aroma yoğunluğu, karışık flora nedeniyle oluşmaktadır. Ayrıca lezzet ve aroma yoğunluğunu, ev yapımı dana rennet özleri kullanımı ve çevresel flora da etkilemektedir (Hayaloğlu ve Kirbağ, 2007). Aşağıda Türkiye'de farklı yöntemler ile üretilen bazı yöresel küflü peynirlerin yapılışı özetlenmiştir. 
Divle tulum peyniri: Karaman ili civar bölgelerinde üretilmektedir. Diğer tulum peynirlerinden farklı olarak peynir telemesinin yıkanması, elde edilen peynirin olgunlaştırılması için yörede bulunan ve içerisinde kendine özgü yerleşik küf florası bulunan Divle Obruğu olarak isimlendirilen mağaraya konulmasıdır. Diğer bir fark ise mağaraya konulan peynir tulumları üzerlerinde yaklaşı 1 ay sonra önce mavi, sonra beyaz ve daha sonra da kırmızı renkli küf florasının üremesidir (İşleyici ve ark., 2011; Morul ve İşleyici, 2012). Üretiminde herhangi bir starter kültür kullanılmamakla birlikte Divle obruğunun doğal florasındaki küfler bu renk değişimine neden olmaktadır (Öztürkoğlu-Budak ve ark., 2016a). Oluşan küf kuruduktan sonra tulumun diş yüzeyinin üreyen küfün rengini alması, peynirin tam olarak olgunlaştığının göstergesi olarak kabul edilmektedir. Peynirin olgunlaşma süresi 5-6 aylık bir süreyi kapsamaktadır (İşleyici ve ark., 2011; Morul ve İşleyici, 2012).

Konya küflü peyniri: Konya ve çevresinde üretilir. Geleneksel olarak üretiminde süt mayalanır, elde edilen pıhtı süzülerek temiz keçi veya koyun tulumuna doldurularak yaklaşık bir hafta bekletilir. Peynirler olgunlaşması için 3-4 ay serin ortamda depolanır. Kültürlü yapım şeklinde ise yağsız taze koyun peyniri \%4 tuz ilave edilerek kurutulur. Kurutulan peynirler ambalajlanır ve $0-4{ }^{\circ} \mathrm{C}$ 'deki depoya alınarak 45 gün bekletilir. 45 gün sonra peynirler ufalanarak üzerine 8-10 ${ }^{\circ} \mathrm{C}$ 'de muhafaza edilen Penicillium roqueforti küf kültürü püskürtülür. Peynir 20-25 gün küflenmesi için bekletilir (Özgören ve Seçkin, 2012).

Göğermiş küflü peyniri: Erzurum ve bölgesinde üretilen Göğermiş küflü peyniri iki farklı şekilde yapılmaktadır. Göğermiş peynirinin birinci yapım şeklinde peynir, Civil peyniri (\%70-75) ve lor peyniri (\%30-25) karıştırılarak yapılırken ikinci yapım şeklinde sadece Civil peyniri kullanılmaktadır. Her iki üretim şeklinde de peynirler tuzlandıktan sonra plastik bidonlara basılarak ağzı sıkıca kapatılır. Plastik bidonların kapakları delinerek ya da cendere bezi konularak ters çevrilir ve peynirin suyunun ayrılması sağlanır. Bidonlar $8-12{ }^{\circ} \mathrm{C}$ 'de küf gelişimi oluşuncaya kadar (en az 60 gün) depolanmaktadır (Çakmakçı, 2011; Özgören ve Seçkin, 2012).

Kayseri çömlek peyniri: Üretiminde taze süzülmüş peynir kullanılmaktadır. Temiz soğuk suda bekletilen peynirin, peyniraltı suyu uzaklaştırılır ve sudan çıkarılan peynir $60-65{ }^{\circ} \mathrm{C}$ 'deki suda haşlanır. Elde edilen peynir elle ufalanır, tuzlanır, isteğe bağlı olarak çörekotu ilave edilerek 1-2 kg'lık küplere boşluk kalmayacak şekilde basılır. Çömleğin ağzına 2-3 cm kalınlıkta içyağ doldurularak kapatılır ve serin bir yerde çömlek baş aşağ gelecek şekilde kumun içerisine gömülerek muhafaza edilir. Olgunlaşma süresi 3-4 aydır. İsteğe bağlı olarak doğal ortam koşullarında starter kültür kullanılmadan küflendirilerek veya küflendirilmeden de tüketilebilmektedir (Kamber ve Terzi, 2008; Özgören ve Seçkin, 2012).

Tomas peyniri: Bingöl, Tunceli, Elazı̆̆, Muş ve Erzurum illerinde üretilen başka bir küflü peynir çeşidi yöreye göre Tomas, Serto ve Karın kaymağı olarak adlandırılmaktadır. Tomas peynirinin üretiminde, ilk olarak çiğ sütten yoğurt üretilmekte ve yoğurt yayıklanarak tereyağı elde edilmektedir. Yayıklama sonrası geriye kalan ayran Tomas peyniri yapımında kullanılmaktadır. Peynirin üretiminde ayranın 1sitılması sonucunda oluşan çökeleğe, tereyağı, kaymak, süt ve yoğurt karıştırılarak yoğrulur. Daha sonra deri tulumlara basılarak 3-4 aylık olgunlaştırılır. Tomas peyniri kendi tulumundan çıkartılarak tekrar tereyağı ve süt ilave edilerek özel olarak hazırlanmış tulumlara hava almayacak şekilde basılır ve ağzı kapatılarak serin yerlerde muhafaza edilerek küf türlerinin gelişmesi ile yeşil renk alarak olgunlaştırılır (Gündüz, 1982).

\section{Peynirde Küfün Önemi}

Küfler, peynir mikrobiyolojisinde hem starter kültür olarak olgunlaştırmada kullanılmaları hem de ürünü bozabilmeleri veya mikotoksin üretmeleri nedeniyle önem taşımaktadırlar. Peynirlerde starter olarak kullanılan veya çevreden bulaşmış olan $P$. roqueforti, $P$. camemberti gibi küflerin ortamdaki asidik molekülleri asimile ettikleri ve salgıladıkları ekstraselüler proteinaz enzimleri ile $\alpha-s_{1}$ ve $\beta$-kazeini parçalayarak tamponlama yapan bileşikler oluşturabildikleri rapor edilmiştir (Andiç ve ark., 2010). Avrupa ülkelerinde ve Kuzey Amerika'da küfler ile olgunlaştırılan peynirlerin tüketimi çoktur. Peynirde küflerin meydana getirdiği reaksiyonlar bu peynirlere özgü koku ve tadın oluşumundan sorumludur (Gürsoy ve Kesenkaş, 2011). Örneğin Divle peynirinin olgunlaşması sırasında başta yeşil sonra kırmızı renk alması, keskin aroması ve kolay ufalanan tekstürü doğal florasında bulunan küfler ile elde edilmektedir (Öztürkoğlu-Budak ve ark., 2016b). Küflerin geniş enzim sistemleri ile olgunlaştırmayı hızlandırdığ çalışmada $P$. roqueforti'nin starter kültür olarak kullanımının lor peyniri katılmadan üretilen Civil peynirinde proteolizi hızlandırdı ̆̆ (Çakmakçı ve ark., 2014) Ayrıca küflü peynirlerdeki küflerin bazı hastalıklara karşı direnç sağladığı inancı da oldukça yaygındır (Özkalp ve Durak, 1998; Şengün ve ark., 2006; Çakmakçı, 2011).

Küfler, belirtilen faydalarının yanında peynirde istenmeyen küflerin gelişimi ile renk, tat-koku değişikliklerine neden olarak önemli kalite kayıplarına ve ekonomik kayıplara neden olmaktadır (Gürsoy ve Kesenkaş, 2011; Özçakmak ve Dervişoğlu, 2011). Ayrıca bu küflerin mikotoksin oluşturma riskleri de mevcuttur. Peynirde bozulma etmeni küfler arasında Penicillium, Cladosporium; Aspergillus, Mucor, Fusarium, Monilia ve Alterneria cinslerine ait türler yer almaktadır (Gürsoy ve Kesenkaş, 2011). Bu küflerin gelişimini engellemek için koruyucular kullanılabilmektedir. Sorbik asit veya bunların tuzları, bozulma etmeni küflerin önlenmesi için peynir yüzeylerine uygulanabilmektedir. Doğal antimikrobiyal maddelerin bu koruyuculara alternatif olabileceği ile ilgili çalışmalar yapılmaktadır. Kekik ve karanfil esansiyel yağlarının Çedar peynirinde $P$. citrinum, Kaşar peynirinde A. flavus, zeytin yaprağ 1 ekstraklarının ise Tulum peynirinde $A$. niger, $P$. citrinum ve $P$. roqueforti, beyaz peynirde $M$. racemosus'un gelişimini inhibe edebildiği belirtilmiştir (Özçakmakcı ve Dervişoğlu, 2011).

\section{Küflü Peynirlerde Mikotoksin Riski}

Kontrolsüz şartlarda üretilen ve olgunlaştırılan küflü peynirler insan sağlığını olumsuz etkileyen ve Aspergillus, Penicillium, Fusarium ve Alternaria spp. başta olmak üzere küfler tarafindan üretilen mikotoksinler açısından risk taşımaktadır (Yetim ve Çakmakçı, 1997; 
Kabak ve Var, 2006; Sağdıç ve ark., 2008, Çakmakçı ve ark., 2012). Yapılan araştırmalar sonucu peynirlerde karşılaşılan başlıca mikotoksinlerin, aflatoksin, sitrinin, okratoksin A, siklopiazonik asit, mikofenolik asit, rokfortin ve rokfortin $\mathrm{C}$ olduğu bildirilmiştir (Erdoğan ve ark., 2003; Gürses ve ark., 2004; Tekinşen ve Tekinşen, 2005; Kireçci ve ark., 2007; Erkan ve ark., 2009; Aydemir-Atasever ve ark., 2010; İşleyici ve ark., 2011, Çakmakçı ve ark., 2012; Dinçoğlu ve ark., 2012; Var ve ark., 2015). Peynirin yüzeyinde bulunan veya zamanla peynirin iç kısımlarına nüfuz etmiş olan mikotoksinler karaciğer ve böbrek bozuklukları, sinir sistemi ve bağışıklık sistemi bozuklukları, deri duyarlılığı veya nekrozu gibi ciddi sağlık sorunlarına yol açabilmektedir (Topal, 1986; Sağdıç ve ark., 2008; İşleyici ve ark., 2011; Güley ve ark., 2013). Sütte en sik rastlanan aflatoksin $\mathrm{M}_{1}{ }^{\prime}$ in $\left(\mathrm{AFM}_{1}\right)$, aflatoksin $\mathrm{B}_{1}\left(\mathrm{AFB}_{1}\right)$ ile kontamine yemler ile beslenen süt hayvanlarının bu yemlerdeki bu mikotoksini metabolize ederek monohidroksi türevi olan $\mathrm{AFM}_{1}$ şekline dönüştürmesi ile oluştuğu rapor edilmiştir (Bulca ve Bircan, 2013). Peynire mikotoksinlerin diğer bulaşma yolu ise direkt küf kontaminasyonuna maruz kalmalarıdır (Kırdar, 2006). Özellikle kontrolsüz şartlarda üretilen peynirlerde yapılan analizlerde aflatoksin varlığı rapor edilmiştir (İşleyici ve ark., 2011; Var ve ark., 2015). Aspergillus cinsi içerisinde yer alan A. flavus, $A$. parasiticus, ve $A$. nomius gibi türler tarafindan üretilen aflatoksinlerin toksik, bağışıklık sistemi baskılayıcı, karsinojenik, mutajenik ve teratojenik etkiler oluşturduğu bildirilmiştir (Gürses ve ark., 2004; Tekinşen ve Tekinşen, 2005; Kireçci ve ark., 2007; Erkan ve ark., 2009; Aydemir-Atasever ve ark., 2010; İşleyici ve ark., 2011).

Güley ve ark. (2013) doğal yolla küflendirilen bazı geleneksel peynirlerde aflatoksin üreten küflerin varlığını araştırmıştır. Çoğu Konya küflü peyniri olmak üzere toplam 11 adet küflü peynir örneği toplamışlardır. İzole edilen 27 adet küfün tamamının Penicillium cinsine ait türler olduğu belirlenmiştir. $\mathrm{Bu}$ çalışmada yapılan izolasyon ve tanımlama sonucunda toksin üreten Aspergillus türlerine rastlanmamıştır. Özgören ve Seçkin (2016)'de Türkiye'nin farklı kentlerinden topladığı 100 adet küflü peyniri aflatoksin $\mathrm{M}_{1}$ bakımından araştırmış ve 52 örnekte 10,6 ile 702 ng/kg arasında değişen miktarlarda aflatoksin M1 varlığını ELISA tekniği ile tespit etmiştir. Çakmakci ve ark. (2015) tarafından yapılan diğer bir çalışmada ise küflü Civil peynirlerinden izole edilen 140 adet $P$. roqueforti suşu patulin, mikofenolik asit, rokfortin $\mathrm{C}$ ve penisilik asit gibi mikotoksinleri üretip üretmedikleri açısından araştırılmıştır. Bazı suşların birden fazla mikotoksini ürettiği tespit edilmiştir.

\section{Peynirlerden Küflerin İzolasyonu ve Tanımlanmasında Kullanılan Yöntemler}

Ülkemizde üretilen peynirlerden küflerin izolasyonu için araştırmacılar tarafindan \%10 tartarik asit veya laktik asit ile pH'sı 3,5'e ayarlanmış Potato Dextrose Agar (PDA) ve Malt Ekstrakt Agar (MEA), Czapek Dox Agar (CDA), Rose Bengal Chloramphenicol Agar ( RBC) kullanılmıştır. Genellikle uygun dilüsyonlarda hazırlanmış peynir örneklerinden yayma plak yöntemine göre ekim yapılmıştır. Ekim yapılan petriler $25-30^{\circ} \mathrm{C}$ sicaklıklarda 5-10 gün süre ile inkübasyona bırakılmıştır. İnkübasyon süresi sonunda küf kolonilerini MEA ve PDA'ya ekim yapılarak saflaştırılmıştır. Makroskobik ve mikroskobik tanımlama için MEA, Czapek Yeast EkstractAgar (CYA), \%25 Gliserin Nitrat Agar (G25N), Yeast Extract Sucrose Agar (YESA), CDA, PDA ve Sabouraud Dextrose Agar (SDA) gibi çeşitli besiyerleri kullanılmış saflaştırılmış küf izolatlarından üç nokta yöntemine göre bu besiyerlerine ekim yapılmıştır. İnkübasyon sonundan gelişen küfler morfolojik olarak koloninin şekli, çap1, yüzey görünümü, yap1s1, rengi, eksuda meydana getirip getirmediği, besiyerinde pigment oluşturup oluşturmadığına göre makroskobik olarak tanımlama yapılmıştır. Küf izolatlarından laktofenol çözeltisi ile hazırlanan preparatların mikroskop ile sporların büyüklügüu, şekilleri, sporların zar içinde veya serbest oluşları, eşeyli veya eşeysiz oluşumları, spor üreten yapıların farklılıkları, hiflerin bölmeli veya bölmesiz oluşuna göre mikroskobik olarak tanımlamaları yapılmıştır (Şengün ve ark., 2006; Hayaloglu ve Kirbağ, 2007; Sağdıç ve ark., 2008; Pekel ve Korukluoğlu, 2009; Çakmakçı ve ark., 2012). Tablo 1'de Türkiye'de geleneksel ve ticari olarak üretilen peynirlerden küflerin izolasyonu ve tanımlanması için araştırmacıların kullandıkları kullanılan yöntemler ve ortam şartları gösterilmiştir.

Tablo 1 Küflü peynirlerin küf florasının belirlenmesinde kullanılan yöntemler

\begin{tabular}{l|lll}
\hline Araştırmacılar & Kullanılan Yöntem & Kullanılan Besiyerleri & Ortam Şartları \\
\hline Öztürkoğlu- Budak ve ark. 2016a & MMM & PDA, MAE & $28^{\circ} \mathrm{C}, 5-7$ gün \\
Cakmakc1 ve ark., 2012 & MMM & PDA $(\% 10$ tartarik asit pH3.5) CDA & $25^{\circ} \mathrm{C} 5$ gün \\
Pekel ve Korukluoğlu, 2009 & MM & PDA, MAE, CYEA, \%25 GNA & $30^{\circ} \mathrm{C} 7$ gün \\
Sağdıç ve ark., 2008 & MM & MEA, CDA & $25^{\circ} \mathrm{C} 5-14$ gün \\
Hayaloglu ve Kirbağ 2007 & MP & MEA, YESA, CDA, PDA, SDA & $25^{\circ} \mathrm{C}, 7$ gün $30^{\circ} \mathrm{C}, 7$ gün \\
Şengün ve ark.,2006 & MYM & PDA & $30^{\circ} \mathrm{C}, 5$ gün \\
Erdogan ve ark., 2003 & MMK & CA, YESB & $5^{\circ} \mathrm{C}, 12^{\circ} \mathrm{C}$ ve $25^{\circ} \mathrm{C}, 10$ gün \\
Özkalp, 1998. & MM & MEA, CYA, CDA & $25^{\circ} \mathrm{C}, 5-14$ gün \\
Özkalp ve Durak, 1998 & MM & MEA, CDA & $25^{\circ} \mathrm{C}, 5-14$ gün \\
Bostan ve ark., 1992 & MM & MEA, PDA & $28^{\circ} \mathrm{C}, 2$ gün \\
Sert, 1992 & MM & ARBA, CA, PDA & $25^{\circ} \mathrm{C}, 10$ gün \\
Gündüz, 1982 & MM & Asitlendirilmiş PDA & $25^{\circ} \mathrm{C}, 10$ gün \\
Demirer 1974 & MM & ARBA, CA, PDA, SDA, YESA & $27^{\circ} \mathrm{C}, 3-7$ gün \\
\hline
\end{tabular}

MMM: Makroskobik,+ mikroskobik + moleküler, MM: Makroskobik +mikroskobik, MP: Morfolojik yapı+ pigmentler, MYM: Morfolojik yapılar +mikroskobik, MMK: Morfolojik, mikroskobik ve kromotografik, PDA: PotatoDextroseAgar, CDA: CzapexDoxAgar, MEA: Malt ExtractAgar, CYEA: ChapekYeastEkstraktAgar, GNA: Gliserin Nitrat Agar, YESA: YeastExtractSucroseAgar, SDA: SabouraudDextroseAgar, CA: CzapexAgar, YESB: YeastExtractSucroseBroth, CYA: CzapekYeasyAutolysate, ARBA: ArabinozRoseBengalAgar 


\section{Türkiye’de Üretilen Küflü Peynirlerin Küf Florası}

Türkiye'de üretilen küflü peynirlerden izole edilen küfler Tablo 2'de verilmiştir. Tablo 2'de görüldüğü gibi küfle olgunlaştırılan peynirlerde hâkim florayı Penicillium spp. oluşturmaktadır. Bunun yanında Aspergillus, Alternaria, Mucor, Geotrichum, Cladosporium cinslerine ait türler de izole edilmiştir

Demirer (1974) Konya küflü tulum peynirlerinden ve Diyarbakır otlu beyaz peynirlerinden ve dış etkenlerle küflenmiş Erzincan tulum peynirlerinin küflü yerlerinden alınmış 71 adet numunede bulunan küfleri izole etmiş ve tanımlamıştır. Çalışmada Erzincan tulum peynirlerinde, Penicillium roquefortii, $P$. crustosum, $P$. notatum, $P$. chrysogenum, Aspergillus manginii, A. versicolor, Cladosporium cladosporiodies, C. herbarum, $C$. macrocarpum, Alternaria alternata ve Wallemia sebi, Konya küflü tulum peynirlerinde, $P$. roquefortii, Diyarbakır otlu beyaz peynirlerinde ise $P$. notatumve $P$. roquefortii izole edilmiştir. Analiz sonuçlarına göre $P$. roquefortii'nin peynir örneklerinde dominant küf türü olduğu belirlenmiştir.

Tomas peynirinin doğal mikroflorası ile ilgili bir araştırmada 20 Tomas peyniri incelenmiștir. Örneklerin tamamından 863 izolat elde edilmiş ve bu izolatların tamamının $P$. roquefortii olduğu belirlenmiştir (Gündüz, 1982).

Özkalp ve Durak (1998) Konya ve civarında üretilen küflü peynirlerin küf florasını araştırmışlardır. Araştırmada 140 küflü peynir örneklerinden toplam 296 izolat elde ederek tanımlama yapmışlardır. Küflü peynir örneklerinden izole ettikleri küflerin tümünün Penicillium $(\% 87,16)$ ve Aspergillus $(\% 12,84)$ cinslerine ait türler olduğunu belirlemişlerdir. Tüm örneklerde dominant tür olarak $P$. roqueforti tanımlanmış ve $\% 42,91$ oranı ile bu tür bulunan türler arasında ilk sırayı almıştır. Küflü peynir örneklerinde yabanc1 flora olarak A. flavus $(\% 8,45)$ ve $A$. versicolor $(\% 4,39)$ 'a rastlanmıştır.

Erdogan ve ark. (2003) Erzurum'da yaptıkları bir çalışmada perakendecilerden sağlanan 12 adet mavi küflü tulum peynirinden toplam 16 adet küf izole etmişlerdir. İzole edilen küflerin 12 tanesini $P$. roquerforti ve 4 tanesini de Geotricum candidum olarak tanımlamışlardır. Şengün ve ark. (2006) geleneksel küflü çömlek peynirinin mikroflorası üzerine yaptıkları çalışmada, Isparta ili merkez pazarlarından ve mandıralardan temin ettikleri 14 adet küflü peynir örneğini incelemişlerdir. Peynir örneklerinden toplam 19 adet farklı koloni özelliği gösteren küf izole edilmiş ve stereomikroskop ile yapılan incelemeler sonucunda bu izolatların yarısından fazlasının $(\% 57,8)$ Penicillium türlerine ait olduğu belirlenmiştir.

Hayaloğlu ve Kirbag (2007) yaptıkları çalışmada 30 küflü peynir örneğini küf çeşidi bakımından incelemişlerdir. Yaptıkları bu çalışmada toplam 24 farklı küf izole edip tanımlamışlardır. En sık izole edilen küf türleri, $P$. commune, $P$. roqueforti, $G$. candidum ve

$P$. verrucosum'dir. Cins olarak en s1k izole edilen Penicillium spp. toplam izolatın \%70,25'ini temsil etmektedir. Diğer izole edilen türlerin ise Alternaria, Acremonium, Aspergillus, Cladosporium, Geotrichum, Mucor, Rhizopus ve Trichoderma cinslerine ait olduğu tespit edilmiş̧ir.

Yapılan diğer bir çalışmada geleneksel yöntemle üretilen küflü peynirlerin mikrobiyolojik nitelikleri ve küf florası araştırılmıștır. Karaman, Konya, Mersin, Nevşehir ve Niğde'den toplanan 21 küflü peynir örneğinden 35 adet küf izole edilmiş, makroskobik ve mikroskobik incelemeler sonucunda küfler, G. candidum, P. citrinum, $P$. chrysogenum, $P$. expansum, $P$. roquerfortii, $P$. verrucosum, Penicillium spp. ve Thamnidium spp. olarak tanımlanmıştır. $\mathrm{Bu}$ araştırmada $P$. roquerfortii örneklerden en çok izole edilen baskın tür olmuştur. En az izole edilen küf türü ise Thamnidium spp. olup sadece bir örnekten izole edilmiştir (Sağdıç ve ark., 2008).

Küflü Civil peynirinde yapılan bir çalıșmada, Erzurum'dan sağlanan 41 küflü civil peynir örneğinden 186 izolat elde edilmiş ve küf kolonileri geleneksel ve moleküler yöntemlerle tanımlanmıştır. Suşların makroskobik ve mikroskobik özellikler bakımından değerlendirilmesi sonucunda 186 izolatın tamamı Penicillium cinsine ait olup, baskin türün $P$. roquerforti olduğu belirlenmiştir (Çakmakcı ve ark., 2012).

Öztürkoğlu-Budak ve ark. (2016a) tarafindan yapılan bir çalışmada Divle peynirinin olgunlaşma aşamalarında mikrobiotası moleküler yöntemler ile araştırılmış ve Penicillium polonicum, $P$. biforme, $P$. roqueforti, $P$. chrysogenum ve Debaryomyces hansenii türleri en s1k izole edilen türler olarak tanımlanmıştır.

\section{Diğer Yöresel Peynir Çeşitlerinin Küf Florası}

Doğal üretim şartlarında küfle olgunlaştırılmayan fakat küf gelişimi olan peynirlerde saptanan küf floras1 üzerine yapılan araştırmalar Tablo 3 'te verilmiş̧ir.

Pekel ve Korukluoğlu (2009) Küp peynirinin mikrobiyolojisi ile ilgili yaptıkları bir araştırmada, incelenen 25 adet küp peyniri örneğinden elde edilen 31 küf izolatını tanımlamışlardır. Küf izolatlarının tamamının Penicillium ve Aspergillus cinslerine ait türler olduğu tespit edilmiştir. 29 suşun Penicilium cinsine ait olduğu belirlenmiş, 15 tür tespit edilmiştir. En fazla rastlanan tür $P$. chrysogenum olarak belirlenmiştir. Yapılan diğer bir çalışmada Erzincan taze tulum peynir, Erzurum taze beyaz peynir, Civil peyniri ve Kaşar peyniri olmak üzere toplam 51 adet peynir örneğinin küf florası incelenmiştir. Tulum peynirlerinden elde edilen izolatlar, G. candidum, Mucor racemosus, Mucor spp., $P$. roqueforti, $P$. verrucosum var. cyclopium olarak tanımlanmış, 2 izolat ise tanımlanamamıştır. Tulum peyniri örneğinden en fazla izole edilen türün $P$. roqueforti olduğu belirlenmiştir. Beyaz peynirlerde tanımlanamayan 1 izolat hariç, diğer izolatlar C. herbarum, G. candidum, Mucor spp., $P$. roqueforti, $P$. verrucosum var. cylopium olarak tanımlanmıştır. Bu türler arasında en yüksek oranda $G$. candidum suşuna rastlanmıștır. Civil peynirinde ise $G$. candidum, M. racemosus, Mucor spp., P. chrysogenum, $P$. roqueforti, $P$. verrucosum var. cyclopium ve diğer Penicillium türleri belirlenmiştir. Civil peyniri örneklerinde de en çok izole edilen küf G. candidum suşu olmuştur. Kaşar peyniri örneklerinden izole edilen küflerin 39'u tanımlanabilmiş, fakat 2'si tanımlanamamıștır. Tanımlanan küfler ise A. niger, $G$. candidum, Mucor spp., P. expansum, P. roqueforti, $P$. verrucosum var. cyclopium ve diğer Penicillium türleridir. Kaşar peynirinde diğer peynirlerden farklı olarak $P$. roqueforti'nin en yüksek oranda bulunduğu bildirilmiştir. Bu sonuçlara bakıldığında Penicillium türlerinin baskın durumda olduğu gözlenmiştir (Sert, 1992). 
Tablo 2 Türkiye'de Üretilen Küflü Peynirlerde Tespit Edilen Küf Florası

\begin{tabular}{|c|c|c|c|}
\hline Küflü Peynir Çeșitleri (Örnek Sayısı) & \multicolumn{2}{|c|}{ İzole Edilen Küfler (\%) } & Kaynak \\
\hline Divle Küflü Peyniri (6) & $\begin{array}{l}\text { Penicillium polonicum, }(\% 15,25) \\
\text { P. roqueforti, }(\% 8,6) \\
\text { P. chrysogenum }(\% 8,6) \\
\text { P. brevicompactum }(\% 4,31) \\
\text { P. commune }(\% 6,03) \\
\text { P. rubens }(\% 3,44) \\
\text { P.cylopium }(\% 6,89) \\
\text { P. cavernicola }(\% 4,31) \\
\text { P. olsoni }(\% 1,72)\end{array}$ & $\begin{array}{l}\text { P.orylophylium }(\% 5,17) \\
\text { P. spinulosum }(\% 1,72) \\
\text { P.crustosum }(\% 1,72) \\
\text { P.fuscoglaucum }(\% 1,72) \\
\text { P.verrucosum }(\% 1,72) \\
\text { Mucor racemosus }(\% 3,44) \\
\text { Mucor flavus }(\% 2,58) \\
\text { Scopulariopsis fusca }(\% 0,86) \\
\text { Trichoderma spp. }(\% 0,86) \\
\end{array}$ & $\begin{array}{l}\text { Öztürkoğlu- Budak ve } \\
\text { ark., 2016a }\end{array}$ \\
\hline Küflü Civil Peyniri (41) & $\begin{array}{l}\text { Penicillium roquerfortii }(\% 92,5) \\
\text { P. commune }(\% 6,98)\end{array}$ & Penicillium sp. $(\% 0,53)$ & $\begin{array}{l}\text { Çakmakcı ve ark., } \\
2012\end{array}$ \\
\hline Küflü Peynir (30) & $\begin{array}{l}\text { Acremonium alternatum }(\% 1,3) \\
\text { Alternaria alternata }(\% 1,9) \\
\text { Aspergillus flavus }(\% 0,6) \\
\text { A. fumigatus }(\% 4,4) \\
\text { A. niger }(\% 1,9) \\
\text { Cladosporium cladosporioides }(\% 1,9) \\
\text { C. herbarium }(\% 1,3) \\
\text { Geotrichium. candidum }(\% 8,2) \\
\text { Mucor hemialis }(\% 1,9) \\
\text { M. mucedo }(\% 1,3) \\
\text { P. brevicompactum }(\% 4,4) \\
\text { P. chrysogenum }(\% 5,7) \\
\text {. }\end{array}$ & $\begin{array}{l}\text { P. citrinum }(\% 5,1) \\
\text { P. commune }(\% 10,1) \\
\text { P. crustom }(\% 3,8) \\
\text { P. echinulatum }(\% 5,1) \\
\text { P. expansum }(\% 6,3) \\
\text { P. roquerfortii }(\% 8,9) \\
\text { P. solitum }(\% 5,1) \\
\text { P. spinolusum }(\% 3,2) \\
\text { P. verrucosum }(\% 9,5) \\
\text { P. viridicatum }(\% 3,2) \\
\text { Rhizopus nigricans }(\% 3,2) \\
\text { Trichoderma harzianum }(\% 1,9)\end{array}$ & $\begin{array}{l}\text { Hayaloğlu ve Kırbağ, } \\
2007\end{array}$ \\
\hline Konya Küflü Peyniri (9) & Penicillium spp. $(\% 100)$ & & Güley ve ark.,2013 \\
\hline $\begin{array}{l}\text { Karaman, Konya, Mersin, Nevşehir } \\
\text { ve Niğde Küflü Peynirleri (21) }\end{array}$ & $\begin{array}{l}\text { Geotrichum candidum }(\% 8,6) \\
P . \text { citrinum }(\% 17,1) \\
P . \text { chrysogenum }(\% 17,1) \\
P . \text { expansum }(\% 5,7)\end{array}$ & $\begin{array}{l}\text { P. roquerfortii }(\% 28,6) \\
\text { P. verrucosum }(\% 6,5) \\
\text { Penicilliumspp. }(\% 14,3) \\
\text { Thamnidium sp. }(\% 2,9) \\
\end{array}$ & Sağdıç ve ark., 2008 \\
\hline $\begin{array}{l}\text { Isparta İli ve Yöresi Geleneksel Küflü } \\
\text { Çömlek Peyniri (14) }\end{array}$ & $\begin{array}{l}\text { Penicillium spp. }(\% 57,8) \\
\text { Aureobasidium spp. }(\% 15,8) \\
\text { Geotrichum spp. }(\% 10,5)\end{array}$ & $\begin{array}{l}\text { Aspergillus spp. (\%5,3) } \\
\text { Rhizopus } \text { spp. }(\% 5,3) \\
\text { Mucor } \text { spp. }(\% 5,3)\end{array}$ & $\begin{array}{l}\text { Şengün ve ark., } \\
2006\end{array}$ \\
\hline Mavi Küflü Tulum Peyniri (12) & P. roquefortii $(\% 75)$ & G. candidum (\%25) & Erdoğan ve ark., 2003 \\
\hline $\begin{array}{l}\text { Konya ve Civarı Küflü Peynirler } \\
(140)\end{array}$ & $\begin{array}{l}\text { P. roqueforti }(\% 42,91) \\
\text { P. verrucosum var. cyclopium }(\% 22,3) \\
\text { P. camembertii }(\% 5,07) \\
\text { P. brevicompactum }(\% 4,72) \\
P . \text { chrysogenum }(\% 4,72)\end{array}$ & $\begin{array}{l}\text { P. frequentans }(\% 4,05) \\
\text { P. echinulatum }(\% 3,37) \\
\text { A. flavus }(\% 8,45) \\
\text { A. versicolor }(\% 4,39)\end{array}$ & $\begin{array}{l}\text { Özkalp ve } \\
\text { Durak,1998 }\end{array}$ \\
\hline Tomas Peyniri (20) & P. roquefortii $(\% 100)$ & & Gündüz, 1982 \\
\hline Konya Küflü Tulum Peynirleri (91) & $\begin{array}{l}P . \text { roquefortii }(\% 87,83) \\
P . \text { chrysogenum }(\% 1,35) \\
P . \text { notatum }(\% 4,05)\end{array}$ & $\begin{array}{l}\text { P. crustosum }(\% 1,35) \\
\text { Aspergillus manginii }(\% 0,67)\end{array}$ & Demirer, 1974 \\
\hline
\end{tabular}

Tablo 3 Türkiye'de Üretilen Küf İle Olgunlaştırılmayan Peynirlerde Tespit Edilen Küfler

\begin{tabular}{|c|c|c|c|}
\hline Peynir Çeşitleri (Örnek sayısı) & İzole Ed & Küfler (\%) & Kaynak \\
\hline Küp Peyniri (25) & $\begin{array}{l}\text { Aspergillus versicolor }(\% 6,5) \\
\text { Penicillium arenicola }(\% 3,2) \\
P . \text { aurantiogriseum }(\% 6,4) \\
\text { P. brevicompactum }(\% 6,4) \\
\text { P. camembertii }(\% 3,2) \\
P . \text { chrysogenum }(\% 19,3) \\
P . \text { citrinum }(\% 3,2) \\
P . \text { commune }(\% 3,2)\end{array}$ & $\begin{array}{l}\text { P. fellutanum }(\% 3,2) \\
\text { P. griseofulvum }(\% 6,4) \\
\text { P. janthinellum }(\% 3,2) \\
\text { P. oxalicum }(\% 3,2) \\
\text { P. palitans }(\% 3,2) \\
\text { P. roqueforti }(\% 16,1) \\
\text { P. } \operatorname{solitum}(\% 3,2) \\
\text { P. verrucosum }(\% 9,6)\end{array}$ & $\begin{array}{l}\text { Pekel ve Korukluoğlu, } \\
2009\end{array}$ \\
\hline Erzurum Tulum Peyniri (14) & $\begin{array}{l}\text { Alternaria alternata }(\% 2,86) \\
\text { Geotrichum candidum }(\% 8,57) \\
\text { P.verrucosum var. cyclopium }(\% 20)\end{array}$ & $\begin{array}{l}\text { Mucor } \mathrm{spp} .(\% 22,86) \\
\text { P. roqueforti }(\% 25,71) \\
\text { Mucor racemosus }(\% 5,71)\end{array}$ & Sert, 1992 \\
\hline Erzurum Taze Beyaz Peynirleri (13) & $\begin{array}{l}\text { Cladosporium herbarum }(\% 6,45) \\
\text { G. candidum }(\% 29,03) \\
\text { Mucor } \text { spp. }(\% 19,35)\end{array}$ & $\begin{array}{l}\text { P. roqueforti }(\% 16,13) \\
\text { P. verrucosum var.cyclopium }(\% 19,35)\end{array}$ & Sert, 1992 \\
\hline Erzurum Taze Civil Peyniri (13) & $\begin{array}{l}\text { Penicillium chrysogenum }(\% 6,89) \\
\text { P. roqueforti }(\% 13,79) \\
\text { P. verrucosum var. Cyclopium }(\% 20,69) \\
\text { Penicillium spp. }(\% 3,45)\end{array}$ & $\begin{array}{l}\text { G. candidum }(\% 31,03) \\
\text { M. racemosus }(\% 6,89) \\
\text { Mucor } \operatorname{spp} .(\% 17,24)\end{array}$ & Sert, 1992 \\
\hline Ticari Tulum Peyniri (20) & $\begin{array}{l}\text { Penicillium roqueforti }(\% 35,29) \\
\text { Geotrichum candidum }(\% 43,13)\end{array}$ & $\begin{array}{l}\text { Penicillium spp. }(11,76) \\
\text { Mucor } \text { spp. }(\% 9,80)\end{array}$ & Bostan ve ark., 1992 \\
\hline Kaşar Peyniri (49) & $\begin{array}{l}\text { Penicillium spp. }(\% 86,1) \\
\text { Mucor racemosus }(\% 10,9)\end{array}$ & Aspergillus spp $(\% 3,0)$ & Topal, 1987 \\
\hline $\begin{array}{l}\text { Diyarbakır Otlu Beyaz Peynirleri (10) } \\
\text { Erzincan Tulum Peynirleri (71) }\end{array}$ & $\begin{array}{l}\text { A. versicolor }(\% 1,35) \\
\text { Cladosporium herbarum }(\% 0,67) \\
\text { C. cladosporioides }(\% 0,67)\end{array}$ & $\begin{array}{l}\text { Alternaria alternata }(\% 0,67) \\
\text { Wallemia sebi }(\% 0,67)\end{array}$ & Demirer, 1974 \\
\hline
\end{tabular}


Tulum peynirlerinde yapılan diğer bir çalıșmada ise ticari olarak üretilmiş 20 tulum peynirinden 51 küf izole edilmiştir. İzole edilen küfler $G$. candidum, $P$. roqueforti, diğer Penicillium spp. ve Mucor spp. olarak tanımlanmış ve piyasadan temin edilen iyi kalitede tulum peynirlerinden izole edilen küf türleri arasında $G$. candidum ve $P$. roqueforti'nin en fazla izole edilen küfler olduğu ifade edilmiştir (Bostan ve ark., 1992). Kaşar peynirinin olgunlaştırılması ve depolama aşamasında yüzeyde gelişen küf florasının belirlenmesi üzerine yapılan bir araştırmada, yüzey küfleri içinde Penicillium türlerinin baskın florayı oluşturduğu bildirilmiştir. $P$. verrucosum var. cyclopium en s1k izole edilen suş olmuştur. Diğer saptanan küf türleri ise $M$. racemosus, $A$. versicolor ve A. flavus olarak tespit edilmiştir (Topal, 1987).

\section{Sonuç}

Peynirlerden yaygın olarak izole edilen küf türleri $P$. roqueforti, P.commune, $P$. verrucosum, $P$. palitans $G$. candidum ve $A$. flavus'tur. Geleneksel yöntemler ile üretilen küflü peynirler kontrolsüz şartlarda küflenmeye bırakıldığı için, ortamda istenen küflerin yanı sıra istenmeyen küflerin de gelişebilme riski söz konusudur. $\mathrm{Bu}$ durum mikotoksin riskini ortaya çıkarmaktadır. Ayrıca istenmeyen küflerin gelişmesi peynir üreticileri açısından da önemli kalite problemlerine ve ekonomik kayıplara neden olmaktadır.

Ülkemizde küfle olgunlaştırılan peynirlerdeki mikotoksin oluşturmayan ve peynirde istenilen aroma ve renk oluşumunu sağlayabilen küf suşlarının belirlenmesi ve starter olarak kullanılması için yapılacak araştırılmalar arttırılmalıdır. Bu suşların tespiti ve peynir üretimi sırasında mikotoksin oluşturma özelliklerinin araştırılması halk sağlığı açısından önemlidir. Bunun yanında geleneksel yollar ile üretilen peynirlerdeki aroma ve diş görünümün starter kültürler ile üretilen peynirlerde de sağlanması gerekmektedir.

\section{Kaynaklar}

Akalın S. 2011. Peynirin Beslenme ve Sağlık Etkisi. Peynir Biliminin Temelleri, Ed: Hayaloğlu, A.A., Özer, B. İzmir, Sidas, 643s.

Andiç S, Tunçtürk Y, Gençcelep H. 2010. Dondurarak depolama ve vakum ambalajlamanın Motal peynirinde lipoliz ve organik asit değişimi üzerine etkisi. Gıda, 35 (6) : 423-430.

Anonim. 2013. Türk Gıda Kodeksi Gıda Katkı Maddeleri Yönetmeliği. (30/6/2013 tarihli ve 28693 sayılı Resmî Gazete.)

Anonim. 2015. Türk Gıda kodeksi Peynir Tebliği. 8 Şubat 2015. http://www.resmigazete.gov.tr/eskiler/2015/02/2015020816.htm. [Erişim: 17.03.2016].

Aydemir-Atasever M, Adigüzel G, Atasever M, Özturan, K. 2010. Determination of aflatoxin $\mathbf{M}_{1}$ levels in some cheese types consumed in Erzurum-Turkey. Kafkas Univ. Vet. Fak. Derg., 16 (Suppl-A) : 87-91.

Bostan K, Uğur M, Çiftçioğlu G. 1992. Tulum peynirlerinde laktik asit bakterileri ve küf florası. İstanbul Üni. Vet. Fak. Derg., 17 (2) :111-118.

Bulca S, Bircan C. 2013. Peynirlerde aflatoksin $M_{1}$ varlığ 1 ve aflatoksın $\mathrm{M}_{1}$ konsantrasyonu üzerine etki eden faktörler. Adnan Menderes Univ. Ziraat Fak. Derg., 10 (1) : 31 - 38.
Çakmakçı S. 2011. Türkiye Peynirleri. Peynir Biliminin Temelleri, Ed: Hayaloğlu, A.A., Özer, B. Sidas, İzmir, 643s.

Çakmakcı S, Cetin B, Gurses M, Dagdemir E, Hayaloglu AA. 2012. Morphological, moleculer and mycotoxigenic identification of dominant flamentous fungi from moldy Civil cheese. J. Food Protect., 75 (11) : 2045-2049.

Çakmakci S., Hayaloglu AA., Dagdemir E., Cetin B., Gurses M.and Tahmas-Kayhaoğlu, D. 2014. Effects of Penicillium roqueforti and whey cheese on gross composition, microbiology and proteolysis of mould ripened Civil cheese during ripening. Int J. Of Dairy Tech., 67 (4): 594-603.

Çakmakci S, Gurses M, Hayaloglu AA, Cetin B, Sekerci P, Dagdemir E. 2015. Mycotoxin production capability of Penicillium roqueforti in strains isolated from mouldripened traditional Turkish Civil cheese. Food Addit. Contam.(Part A), 32 (2) : 245-249.

Çelik Ş, Uysal Ş. 2009. Beyaz peynirin bileşim, kalite, mikroflora ve olgunlaşması. Atatürk Üni. Ziraat Fak. Derg. 40 (1) : 141-151.

Demirer M.A. 1974. Bazı peynirlerimizden izole ettiğimiz küfler ve bunların aflatoksin yeteneklerinin araştırılması. Ankara Üniv. Vet. Fak. Derg., XXI (1-2) : 180-198.

Dinçoğlu AH, Gönülalan Z, Kök F. 2012. İzmit bölgesinde satışa sunulan peynirlerdeki aflatoksin $\mathrm{M}_{1}$ düzeylerinin Elisa yöntemiyle tespiti. NWSA-Vet. Sci., 7(1) : 1-6.

Elmalı G, Uylaşer V. 2012. Geleneksel gıdalardan Çeçil Peynirinin üretimi ve özellikleri. U.Ü. Ziraat Fak. Derg. 26 (1) : 83-92.

Erdoğan A, Gurses M, Sert S. 2003. Isolation of moulds capable of producing mycotoxins from blue mouldy cheeses produced in Turkey. Int. J. Food Microbiol., 85 : 83-85.

Erkan ME, Vural A, Güran HŞ. 2009. Diyarbakır örgü peynirinde aflatoksin $M_{1}$ ile verotoksin 1 ve 2 varlığının araştırılması. Dicle Üniv. Vet. Fak. Derg., 1(1) : 19-25.

Güley Z, Uysal HR, Kılıç S. 2013. Doğal yolla küflendirilen bazı geleneksel peynirlerde aflatoksin $M_{1}$, aflatoksin $B_{1}$ ve aflatoksin üreten küflerin varlığının araştırılması. Ege Üniv. Ziraat Fak. Derg.,50 (2): 145-152.

Gündüz HH. 1982. I. Tomas peyniri doğal mikroflorası. Gıda, 5: 227-230.

Gürses M, Erdoğan A, Sert S. 2004. Farklı depolama şartlarının Aspergillus parasiticus NNRL 2999 küf suşu ile aş1lanan tulum peynirlerinde aflatoksin oluşumu üzerine etkisi. Turk J.Vet. Anim. Sci., 28: 233-238.

Gürsoy, O. ve Kesenkaş, H. 2011. Peynir mikrobiyolojisi Peynir Biliminin Temelleri, Ed: Hayaloğlu, A.A., Özer, B. Sidas, İzmir, 643s.

Hayaloğlu AA, Kirbag S. 2007. Microbial quality and presence of moulds in Kuflu cheese. Int. J. Food Microbiol., 115: 376-380.

İşleyici Ö, Sancak YC, Morul F. 2011. Divle tulum peynirinde aflatoksin $\mathrm{M}_{1}$ düzeyi üzerine bir araştırma. Y.Y.Ü. Vet. Fak. Derg., 22(2) : 105-110.

Kabak B, Var I. 2006. Ülkemiz açısından sorun olan mikotoksinler ve riskli gıda maddeleri. Türkiye 9. Gıda Kong., 24-26 Mayıs, Bolu. s. 681-684.

Kamber U, Terzi G. 2008. The traditional cheeses of Turkey: Central Anatolian Region. Food Rev. Int. 24: 74-94.

Kaynar P. 2011. Ülkemiz peynirleri üzerine mikrobiyolojik araştırmalar. Türk Mikrobiyol. Cemiy. Derg. 41 (1) : 1-8.

Kırdar SS. 2006. Süt ve ürünlerinde mikotoksinler. Türkiye 9. Gida Kong.,Bolu, 24-26 Mayıs 2006,. ss. 307-310.

Kireçci E, Savaşçı M, Ayyıldız A. 2007. Sarıkamış’ta tüketilen süt ve peynir ürünlerinde aflatoksin $M_{1}$ varlığının belirlenmesi. İnfeksiyon Derg., 21 (2) : 93-96.

Morul F, İşleyici Ö. 2012. Divle Tulum Peynirinin Kimyasal ve Mikrobiyolojik Özellikleri. YYU Veteriner Fakultesi Dergisi, 2012, 23 (2), 71- 76. 
Özçakmak S, Dervişoğlu M. 2011. Peynirlere kontamine olan küflerin bazı esansiyel yağlar ile inhibizyonu. Gıda, 36 (3) : 177-184.

Özgören E, Seçkin AK. 2012. Türkiye'de ticari ölçekli üretilen küflü peynirlerin kalite özelliklerinin belirlenmesi. Akademik Gida, 10 (2) : 55-62.

Özgören E, Seçkin AK. 2016. Aflatoxin M1 contaminations in mouldy cheese. Mljekarstvo, 66(2), 154-159.

Özkalp B, Durak Y. 1998. Konya ve civarı küflü peynirlerinde küf florasının araştırılması. Turk. J. Biol., 22 : 341-346.

Öztürkoğlu- Budak S, Figge MJ, Houbraken J, de Vries RP. 2016a. The diversity and evolution of microbiota in traditional Turkish Divle Cave cheese during ripening. Int Dairy J,58: 50-53.

Öztürkoğlu-Budak S, Gursoy A, Aykas DP, Koçak C, Dönmez S, de Vries RP, Bron PA. 2016b. Volatile compound profiling of Turkish Divle Cave cheese during production and ripening. J. of Dairy Sci., 99 (7), 51205131.http://dx.doi.org/10.3168/jds.2015-10828

Pekel M, Korukluoğlu M. 2009. Sivas yöresinde üretilen Küp peynirinin mikrobiyolojik, kimyasal kalitesi ve küf florasının belirlenmesi. Anadolu Tarım Bilim. Derg., 24 (1) : $1-7$.

Sağdıç O, Özçelik S, Şimşek B, Özdemir C. 2008. Geleneksel yöntemle üretilen küflü peynirlerin mikrobiyolojik nitelikleri ve küf florası. Türkiye 10. Gıda Kong., Erzurum. 21-23 Mayıs 2008, ss. 709-712.
Sert S. 1992. Bazı peynir çeşitlerinde küf florası ve aflatoksin içerikleri ile aflatoksin potansiyellerinin araştırılması: I. Küf floras1 (I). Atatürk Üniv. Ziraat Fak. Derg. 23 (2) : 89-100.

Şengün IY, Karapınar M, Yaman DB, Yenice E. 2006. Isparta ili ve yöresine ait geleneksel küflü çömlek peynirinin mikroflorası üzerine bir araştırma. Türkiye 9. Gıda Kong., Bolu, 24-26 Mayis,. ss. 461-464.

Tarakci Z, Temiz H. 2009. A review of thechemical, biochemical and antimicrobial aspects of Turkish Otlu (herby) cheese Int. J of Dairy Tech. 62 (3) : 354-360.

Tekinşen KK, Tekinşen OC. 2005. Aflatoxin $M_{1}$ in White pickle and Van otlu (herb) cheeses consumed in southeastern Turkey. Food Control, $16: 565-568$.

Topal Ş. 1986. Gıdalarda bulunan önemli toksik küfler ve sağlık açısından değerlendirilmesi. Gıda, 11 (6) : 345-349.

Topal Ş. 1987. Kaşar peyniri olgunlaşma evresinde gelişen yüzey küfleri ve mikotoksin riskleri. Gıda, 12 (3) : 199-207.

TÜİK (Türkiye İstatistik Kurumu). 2016. Türkiye'de Süt ve süt ürünleri üretimi. Necatibey Cad. No:114, 06100-Ankara. www.tuik.gov.tr [Erişim: 01.09.2016].

Yetim H, Çakmakçı S. 1997. Küfle olgunlaştırılan bazı bitkisel ve hayvansal gidalar. Gida, 22 (4) : 279-285.

Var I, Güney S, Coşkun E, Sağlam S. 2015. Küflü peynirlerde mikotoksin riski. http://www.sutdunyasi.com/haber/1152kuflu-peynirlerde-mikotoksin-riski.html (Erişim: 11.01.2016). 